\title{
Robotic or three-dimensional (3D) laparoscopy for right colectomy with complete mesocolic excision (CME) and intracorporeal anastomosis? A propensity score-matching study comparison
}

\author{
Graziano Ceccarelli ${ }^{1,5} \cdot$ Gianluca Costa $^{2} \cdot$ Valentina Ferraro $^{3} \cdot$ Michele De Rosa $^{1} \cdot$ Fabio Rondelli $^{1,4}$. \\ Walter Bugiantella ${ }^{1}[$
}

Received: 6 January 2020 / Accepted: 23 April 2020

(c) Springer Science+Business Media, LLC, part of Springer Nature 2020

\begin{abstract}
Background We describe our preliminary experience in complete mesocolic excision (CME) with central vascular ligation $(\mathrm{CVL})$ and intracorporeal anastomosis for right colon cancer, comparing the robotic and the three-dimensional (3D) laparoscopic approach.

Methods We performed a retrospective observational clinical cohort study on patients who underwent radical curative surgical resection of right colon cancer with CME from January 2014 to June 2019. Propensity scores were calculated by bivariate logistic regression, including the following variables: age, BMI, and size of tumor.

Results Fifty-five patients underwent CME with CVL: 26 by means of robot-assisted surgery and 29 by means of 3D laparoscopic procedure. There were not statistically significant differences about all the intra- and postoperative outcomes (operative time, length of the specimen, time to bowel canalization, time to soft oral intake, length of hospital stay, postoperative complication, number of retrieved lymph nodes, number of positive lymph nodes and lymph node ratio) between the robotic and the 3D laparoscopic approach. After the matching procedure, 20 patients of the robotic group and 20 patients of the 3D laparoscopic group were selected for the analysis. There were no differences in any of the analyzed variables between the two groups except for longer operative time in the robotic group $(p=0.002)$.

Conclusion The 3D vision revealed an important advantage in order to achieve the correct identification of surgical anatomy allowing a safe and effective right colectomy with CME, CVL, and intracorporeal anastomosis, either using laparoscopic or with robotic approach, providing similar short-term outcomes. Taking into account the high costs and the longer operative time of robotic procedure, the 3D laparoscopy could be considered in performing right colectomy with CME, while the robotic approach should be considered as a first choice approach for challenging situations (obese patient, complex associated procedures).
\end{abstract}

Keywords Complete mesocolic excision $\cdot$ Right colectomy $\cdot$ Robotic surgery $\cdot 3 \mathrm{D} \cdot$ Laparoscopy $\cdot$ Intracorporeal anastomosis

\section{Abbreviations}

CME Complete mesocolic excision

CVL Central vascular ligation

TME Total mesorectal excision
NET Neuroendocrine tumor

OS Overall survival

DFS Disease-free survival
Walter Bugiantella

walterbugiantella@alice.it

1 General Surgery, San Giovanni Battista” Hospital, USL Umbria 2, Via Massimo Arcamone, 1, 06034 Foligno, PG, Italy

2 Emergency Surgery Unit, "Sant'Andrea" Hospital, Sapienza" University of Rome, Via di Grottarossa, 1035, 00189 Roma, Italy
Department of Biomedical Sciences and Human Oncology - Unit Of Endocrine, Digestive And Emergency Surgery, Policlinic of Bari, University "A. Moro" of Bari, Piazza Giulio Cesare, 1, 70124 Bari, Italy

4 Department of Surgical and Biomedical Sciences, University of Perugia, Perugia, Italy

5 General Surgery, ASL Toscana Sud-Est, San Donato" Hospital, Via Pietro Nenni, 1, 52100 Arezzo, Italy 
Complete mesocolic excision (CME) with central vascular ligation (CVL) was first described by Hohemberger and Bokey $[1,2]$. In accordance with the total mesorectal excision (TME) concept, CME involves dissection of colon and corresponding mesocolon along the embryological planes, central division, and ligation of the supplying colonic vessels and removal of adequate colon [3].

There is some evidence that CME for colon cancer is associated with improved oncological outcomes if compared to standard surgery that does not focus on the removal of an intact and complete mesocolon [4, 5].

Minimally invasive surgery has gained worldwide acceptance for the treatment of colonic cancer in the last decade. Many advantages over the traditional open approach have been reported including less pain, shorter hospital stay, quicker return to normal activities, and better cosmetic results, with equivalent long-term oncological results [6-9].

Technological advances have introduced significant improvements in mini-invasive surgery. Currently available technologies include robotically assisted surgery, three-dimensional (3D) and $4 \mathrm{~K}$ high-definition laparoscopic vision systems, several articulated devices, and other features. Threedimensional laparoscopic surgical imaging systems provide stereoscopic depth information that conventional 2D display systems cannot supply. The main advantages of robotic systems include high-definition 3D vision, magnification up to $10 \mathrm{X}$ and the endo-wrist $360^{\circ}$ range of movement for the devices [10-12].

The minimally invasive right colectomy with intracorporeal ileocolic anastomosis (IIA) had a more recent spread ensuring advantages about the postoperative recovery (earlier recovery of digestive function, lower incidence of paralytic ileus, less need of postoperative analgesia, and less postoperative complications), compared with the one with extracorporeal ileocolic anastomosis (EIA) [13, 14]. It requires experience in laparoscopic careful dissection, skill in intracorporeal suturing, and an adequate learning curve: for these reasons, the 3D view (both robotic and laparoscopic) may be a useful device.

Over the last years, several studies have compared the open, laparoscopic, and robotic approach among them for CME [15-22], but to date, no study has ever analyzed the CME in right colectomy comparing the robotic approach with the 3D laparoscopic one. Therefore, we carried out a preliminary case-matched study to compare the robotic and the 3D laparoscopic technological approaches in performing totally minimally invasive right colectomy with CME.

\section{Materials and methods}

We performed a retrospective observational clinical cohort study. Medical charts of patients who underwent radical curative surgical resection of right colon cancer at "San
Donato" Hospital in Arezzo and at "San Giovanni Battista" Hospital in Foligno from January 2014 to June 2019 were reviewed. The search criteria included the following tumor locations: cecum, ascending colon, and hepatic flexure. We selected adenocarcinoma or neuroendocrine tumor (NET) confirmed by pathological examination and with no distant metastasis. Exclusion criteria included colon cancer with distant metastasis, malignant lymphoma, or other non-cancer cases and emergency procedures. Locally advanced tumor as well as concomitant conditions requiring surgical treatment were not considered exclusion criteria. In the attempt to reduce any bias in the research, we considered only the procedures performed by single surgeon (G. Ceccarelli, Chief of Staff Surgeons and Unit Director). The STROBE (Strengthening the Reporting of Observational Studies in Epidemiology) guidelines were used for reporting [23].

All clinical records were reviewed in terms of demographics and clinical variables, procedure details, perioperative outcomes, and oncologic data. Demographics variables included the following: age, gender distribution, body mass index (BMI), ASA classification, comorbidity, and tumor size (considered as the greatest dimension reported in any preoperative workup study). Procedure details included operative time, length of the specimen, time to bowel canalization, time to soft oral intake, length of hospital stay, and postoperative complication (defined as any deviating event documented within 30 days of surgery and arranged by Clavien-Dindo) [24]. A senior staff surgeon (G. Costa) blinded to postoperative course graded the complexity level of any additional procedure similarly to what described by de Santibanes et al. [25]. The elapsed time of concomitant procedure especially for the duration and type of adhesiolysis was also considered for grading the complexity. Briefly, the complexity and duration of the additional procedure was graded from 3 to 7 with the possibility to increase any value by step of 0.25 up to 0.75 for the elapsed time or for more than one procedure such as for example cholecystectomy, and adhesiolysis was performed. No specific enhanced recovery after surgery (ERAS) protocol was adopted. Oncologic data included TNM classification, number of retrieved lymph nodes, number of positive lymph nodes, and lymph node ratio. A formal institutional review board approval was not required because of the un-interventional retrospective design; however, a signed consent for the data treatment and storage for scientific purpose was obtained from all patients (Fig. 1).

All the right colectomies were performed with the same surgical technique both with robotic and laparoscopic approach. The robotic procedures were performed with the da Vinci Si and Xi Systems (Intuitive Surgical, Inc. Sunnyvale, California, USA) placing 3 robotic arms (in left hypochondrium, in umbilicus and in right iliac fossa, respectively) plus one $12 \mathrm{~mm}$ port in left flank (used by 


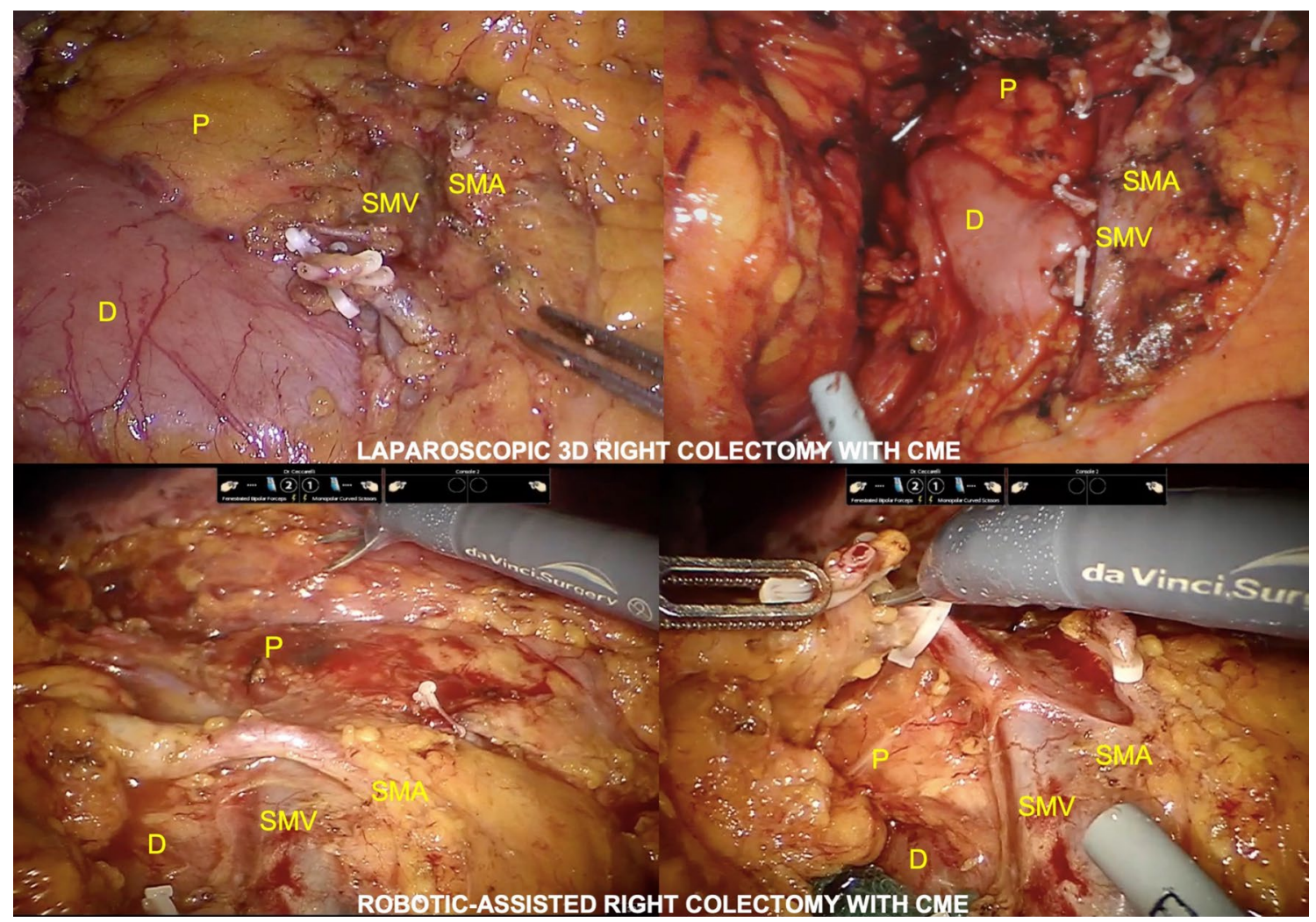

Fig. 1 Key steps of CME in laparoscopic and robotic procedures. $D$ duodenum, $P$ pancreas, $S M V$ superior mesenteric vein, $S M A$ superior mesenteric artery

the bedside assistant). The laparoscopic procedures were performed placing 4 ports in a similar way and using the 3D-HD Viking Camera System (Conmed, Utica, New York, USA). The allocation of patients to either group was based on availability of the robotic system at the time of operation scheduling and/or on patient's preference.

The key steps of the surgical procedure were as follows: identification of the ileocolic pedicle by using a mediolateral approach, incision of the peritoneum along a vertical line to expose the superior mesenteric vein, dissection and preservation of the posterior mesocolic fascia from the duodenum, transection of the ileocolic vessels at the root, medial-to-lateral mobilization of the ascending colon preserving the posterior mesocolon up to and above the head of the pancreas, dissection continued upwards to the right colonic vessels and the gastrocolic trunk, transection of the colic brunch of the gastrocolic trunk, dissection and transection of the right brunch of the middle colic artery at the root, division of the greater omentum, and transection of the bowel about $10 \mathrm{~cm}$ far from the tumor and before the ileocecal valve [26]. The intracorporeal ileocolic side-to-side anastomosis was constructed in isoperistaltic manner with a stapler and the entero-colotomy was sutured in continuous double layer. The mesenteric window was left opened and the specimen was extracted with an endobag through the enlarged periumbilical port incision.

Statistical analysis was performed with SPSS software version 21 (IBM Analytics Italy, Segrate, Milan) integrated with SPSS R Essentials for R Statistical Software version 2.14.2 (Foundation for Statistical Computing, Vienna, Austria). The distribution of continuous variables is reported as mean and standard deviation and/or as median with range when of clinical relevance. Categorical variables are presented as numbers and percentages. Prematching and postmatching data were compared between the two groups. Differences were analyzed using the Mann-Whitney $U$ test for continuous variables. Qualitative data were compared using the Chi-square test with or without Yates' correction or Fisher's exact test when necessary.

Propensity scores were calculated by bivariate logistic regression, including the following variables that might be considered as potential baseline confounders between the groups: sex, age, BMI, size of tumor, and complexity grade of concomitant procedure. We matched propensity scores $1: 1$ with the use of the nearest neighbor methods without replacement by using the closest calipers width to achieve the maximum number of cases without statistical differences in confounders variables. All statistical analyses were 
performed with the two-sided method. Statistical significance was considered with $p$ values of less than 0.05 .

\section{Results}

A total of 185 patients who underwent minimally invasive right colectomy in the study period were selected for this study. Of these, 55 patients undergoing CME with CVL fulfilled the inclusion criteria. Twenty-six were operated by means of robot-assisted surgery and 29 by means of 3D laparoscopic procedure. The mean age was 69.1 years for the robotic group and 75.0 years for the 3D laparoscopic group ( $p=0.046)$.

The mean operative time was $217.7 \mathrm{~min}$ in the robotic group and 170.8 in the 3D laparoscopic group $(p=0.001)$. About the mean operative time, it must be considered that in the robotic group 5 cholecystectomies, 8 adhesiolyses, and 1 direct abdominal wall repair for incisional hernia were performed; while in the 3D laparoscopic group, 7 adhesiolysis, 3 cholecystectomies, and 1 limited resection of the pancreatic tail with splenectomy were performed. The latter was performed because of an incidental pancreatic mass. Definitive pathological examination revealed a papillary cystic neoplasm. Level of complexity was comparable between two groups. No intra-operative complications occurred.

The mean time to bowel canalization was 3.3 days in the robotic group and 3.1 days in the laparoscopic group $(p=0.337)$. The mean time to soft oral intake was 3.3 days and 3.5 days $(p=0.238)$, respectively. The length of postoperative stay was 7.2 days and 8.0 days $(p=0.224)$, respectively.

Postoperative complications occurred in 12 patients (46.2\%) in robotic group: 7 patients had a total of 11 grade I complications (canalization delay with vomiting, anemia, pneumonia, urinary retention, and wound infection); 5 patients had a total of 5 grade II complications (respiratory insufficiency, atrial fibrillation, transitory ischemic attack, postoperative ileus, intra-abdominal bleeding which required blood transfusion in 1 case).

Postoperative complications occurred in 8 patients (27.6\%) in 3D laparoscopic group: 6 patients had a total of 8 grade I complications (canalization delay with vomiting, anemia, transient lymphorrhea, anastomotic bleeding not requiring blood transfusion, pneumonia, and wound infection); 1 patient had grade II complication (intra-abdominal bleeding which required transfusion); and 1 patient had grade III complication (as a consequence of accidental removal of drain on postoperative day three, a fluid collection due to 'biochemical leak' [former defined as grade A pancreatic fistula] requested a percutaneous drainage).

Although higher in the robotic group, the difference in overall morbidity did not reach statistical significance $(p=0.153)$. No mortality within 30 days after surgery was observed in either group.

The total number of retrieved lymph nodes was slightly greater in the robotic group (20.4 vs 18.5 ); however, the difference did not turn out to be statistically significant $(p=0.571)$.

After the propensity score-matching procedure, 20 patients of the robotic group and 20 patients of the 3D laparoscopic group were selected for the analysis. There were no differences in any of the analyzed variables between the two groups, except for the operative time $(p=0.002)$. Although slightly higher after robotic surgery, the overall morbidity rates were comparable between the two groups without statistical significance $(45.0 \%$ vs $25.0 \% ; p=0.320)$. Demographic characteristics, procedure details, postoperative course, and oncologic data of patients' pre- and postpropensity-matching study are shown in Tables 1,2, and 3.

\section{Discussion}

In order to improve the staging and thus the survival of patients affected by colonic cancer, a correct surgical procedure with the removal of all the loco-regional lymph nodes is mandatory. Hoemberger standardized a new surgical technique to completely remove the major number of lymph nodes in colon cancer in 2009 [1]. In accordance with the TME, Hoemberger hypothesized that the number of lymph nodes harvested may serve as a surrogate marker for surgical quality [3]. However, to date, the improving in oncological outcome of CME compared to standard surgery has not been definitively stated yet. Storli in 2013 reported no significant differences in local recurrence and distant metastasis between standard and CME surgery, respectively, but a statistically significant higher OS after CME only for stage I and II [15]. The systematic review by Gouvas in 2016 stated that CME represents the surgical background for the maximum lymph node harvest and an important quality marker for the surgical outcome. However, the review showed that there is a limited evidence that CME colectomy leads to improved long-term survival [27]. More recently, a study of Bertelsen showed that CME slightly improves long-term outcome after resection of stage I-III adenocarcinoma of the right colon [28].

Although no international surgical society has ever recommended right colectomy with CME as "gold standard," we decided to perform such procedure in as many cases as possible thinking that the preoperative workup could not always correctly stage the tumor. The main criteria usually adopted to exclude patients were metastatic disease, ASA $>3$, and frailty condition considered at high risk for major surgery [29]. Despite an extensive policy, less than $30 \%$ of our patients underwent CME. Early in our series, 
Table 1 Demographic characteristics of included patients

\begin{tabular}{|c|c|c|c|c|c|c|}
\hline \multirow[t]{3}{*}{ Demographics } & \multicolumn{3}{|c|}{ Before propensity score matching } & \multicolumn{3}{|c|}{ After propensity score matching } \\
\hline & Robotic & 3D VLS & $p$ & Robotic & 3D VLS & $p$ \\
\hline & $n=26$ & $n=29$ & & $n=20$ & $n=20$ & \\
\hline GE (years, mean, \pm SD) & $69.1( \pm 9.4)$ & $75.0( \pm 11.7)$ & 0.046 & $70.6( \pm 9.9)$ & $74.6( \pm 13.8)$ & 0.301 \\
\hline $\operatorname{Sex}(n, \%)$ & & & 0.091 & & & 1.000 \\
\hline M & $20(76.9 \%)$ & $15(51.7 \%)$ & & $14(70.0 \%)$ & $13(65.0 \%)$ & \\
\hline $\mathrm{F}$ & $6(23.1 \%)$ & $14(48.3 \%)$ & & $6(30.0 \%)$ & $7(35.0 \%)$ & \\
\hline $\mathrm{BMI}($ mean, $\pm \mathrm{SD})$ & $24.4( \pm 3.8)$ & $24.2( \pm 2.8)$ & 0.859 & $23.0( \pm 2.4)$ & $24.1( \pm 2.9)$ & 0.203 \\
\hline ASA score $(n, \%)$ & & & 0.096 & & & 0.673 \\
\hline 1 & $2(7.7 \%)$ & $9(31.0 \%)$ & & $2(10.0 \%)$ & $4(20 \%)$ & \\
\hline 2 & $14(53.8 \%)$ & $13(44.8 \%)$ & & $11(55.0 \%)$ & $10(50 \%)$ & \\
\hline 3 & $10(38.5 \%)$ & $6(20.7 \%)$ & & $7(35.0 \%)$ & $6(30 \%)$ & \\
\hline 4 & 0 & $1(3.4 \%)$ & & 0 & 0 & \\
\hline Comorbidity ( $n$ points, $\%$ ) & & & 0.043 & & & 0.661 \\
\hline Yes & $24(92.3 \%)$ & $20(69.0 \%)$ & & $18(90 \%)$ & $16(80 \%)$ & \\
\hline No & $2(7.7 \%)$ & $9(31.0 \%)$ & & $2(10 \%)$ & $4(20 \%)$ & \\
\hline Associated disease $(n, \%)$ & & & 0.881 & & & 0.997 \\
\hline Cardiovascular & $15(57.6 \%)$ & $17(58.6 \%)$ & & $13(65.0 \%)$ & $12(60.0 \%)$ & \\
\hline Respiratory & $6(23.1 \%)$ & $6(20.6 \%)$ & & $6(30.0 \%)$ & $5(25.0 \%)$ & \\
\hline Diabetes & $5(19.2 \%)$ & $4(13.8 \%)$ & & $5(25.0 \%)$ & $4(20.0 \%)$ & \\
\hline Chronic renal failure & $2(7.7 \%)$ & $1(3.4 \%)$ & & $1(5.0 \%)$ & $1(5.0 \%)$ & \\
\hline Neoplasm & $3(11.0 \%)$ & $1(3.4 \%)$ & & 0 & 0 & \\
\hline Other & $2(7.7 \%)$ & $1(3.4 \%)$ & & 0 & 0 & \\
\hline Tumor size $(\mathrm{cm}$, mean, $\pm \mathrm{SD})$ & $4.1( \pm 1.8)$ & $4.4( \pm 2.1)$ & 0.693 & $4.1( \pm 1.9)$ & $4.0( \pm 2.2)$ & 0.899 \\
\hline
\end{tabular}

we mainly performed robotic surgery. At the present time, since January 2018, we have been working in a large rural area. The Local Health Service is split into two community hospitals which are $15 \mathrm{~km}$ far from each other with only one robotic platform available for both facilities. Since the platform serves a multidisciplinary surgical unit, the robotic use within general surgery is basically reserved for more complex and challenging situations such as upper GI diseases, hepato-biliary-pancreatic surgery, and low rectal cancer. Therefore, the choice to perform robotic or laparoscopic 3D CME right colectomy is strongly influenced by socio-environmental, economic, and organizational factors.

Due to not conclusive evidences with regard to the oncologic outcome, it seems more interesting to debate some technical aspects of CME. About the comparison between standard colectomy and CME both via open or laparoscopic approach, some authors reported no statistically significant differences in postoperative morbidity and mortality while other reports showed that CME may be associated with increased intra-operative organ injuries including more splenic and superior mesenteric vein (SMV) injuries along with severe non-surgical complications.[15, 23-27]. Another controversial technical issue in minimally invasive right colectomy concerns the ileocolic anastomosis. The EIA is easier to perform but it requires a more mobilization and traction of the transverse colon, a larger abdominal incision with higher risk of wound infection and incisional hernia especially in obese patients, and the increasing risk of small bowel mesentery twisting. On the other hands, IIA has the disadvantages that it is time consuming and being technically demanding, it requires advanced skills. Indeed, the anastomotic leak rate seems to be higher even when performed by experienced surgeons [28]. For the above reasons, right CME colectomy with CVL and IIA may be difficult when performed in laparoscopy to such an extent that it was and still is considered one of the most challenging laparoscopic colorectal procedures after Hartmann reversal and low anterior resection with TME [29]. Despite the well- known difficulties, we started to perform IIA in the early 2000s [30]. Nowadays, a survey on the behalf of SICE (Società Italiana di Chirurgia Endoscopica e Nuove Tecnologie - Italian Society of Endoscopic Surgery and New Technologies) showed that a side-to-side isoperistaltic stapled IIA with hand-sewn enterotomy closure is the most frequently adopted technique in Italy to perform ileocolic anastomosis [31].

The role of the robot itself and a comparison of robotic and laparoscopic approach in colorectal surgery has been a subject of several systematic reviews and meta-analysis. Despite promising initial reports, the data from further well-designed studies failed to show high-level evidence 
Table 2 Procedure details and postoperative outcomes of included patients

\begin{tabular}{|c|c|c|c|c|c|c|}
\hline \multirow[t]{3}{*}{ Procedure details and postoperative course } & \multicolumn{3}{|c|}{ Before propensity score matching } & \multicolumn{3}{|c|}{ After propensity score matching } \\
\hline & Robotic & 3D VLS & $p$ & Robotic & 3D VLS & $p$ \\
\hline & $n=26$ & $n=29$ & & $n=20$ & $n=20$ & \\
\hline Operative time (min) & & & 0.001 & & & 0.002 \\
\hline$(\mathrm{Mean} \pm \mathrm{SD})$ & $217.7 \pm 67.2$ & $170.8 \pm 39.6$ & & $225.2 \pm 73.0$ & $165.9 \pm 30.2$ & \\
\hline (Median, range) & $207.5,140-477$ & $169,90-305$ & & $210,140-477$ & $170.5,90-205$ & \\
\hline Complexity of associated procedure (mean $\pm \mathrm{SD})$ & $3.50 \pm 0.55$ & $3.65 \pm 0.77$ & 0.640 & $3.54 \pm 0.60$ & $3.52 \pm 0.51$ & 0.940 \\
\hline Length of specimen $(\mathrm{cm}$, mean $\pm \mathrm{SD})$ & $26.8 \pm 8.8$ & $27.5 \pm 8.9$ & 0.776 & $26.6 \pm 9.1$ & $27.4 \pm 10.0$ & 0.798 \\
\hline Time to bowel canalization (days, mean $\pm \mathrm{SD}$ ) & $3.3 \pm 1.3$ & $3.1 \pm 1.2$ & 0.337 & $3.2 \pm 1.2$ & $3.0 \pm 1.2$ & 0.324 \\
\hline Time to soft oral intake (days, mean $\pm \mathrm{SD}$ ) & $3.3 \pm 1.2$ & $3.5 \pm 1.1$ & 0.238 & $3.2 \pm 1.2$ & $3.5 \pm 1.1$ & 0.475 \\
\hline Length of stay (days, mean $\pm \mathrm{SD}$ ) & $7.2 \pm 1.5$ & $8.0 \pm 2.9$ & 0.224 & $7.2 \pm 1.6$ & $7.8 \pm 3.0$ & 0.110 \\
\hline Postoperative complication ( $n$ points $\%$ ) & & & 0.153 & & & 0.320 \\
\hline Yes & $12(46.2 \%)$ & $8(27.6 \%)$ & & $9(45.0 \%)$ & $5(25.0 \%)$ & \\
\hline No & $14(53.8 \%)$ & $21(72.4 \%)$ & & $11(55.0 \%)$ & $15(75.0 \%)$ & \\
\hline Clavien-Dindo classification ( $n$ points, $\%$ ) & & & 0.400 & & & 0.357 \\
\hline I-II & $12(100.0 \%)$ & $7(87.5 \%)$ & & $9(100.0 \%)$ & $4(80.0 \%)$ & \\
\hline III-IV & $0(0.0 \%)$ & $1(12.5 \%)$ & & $0(0.0 \%)$ & $1(20.0 \%)$ & \\
\hline \multicolumn{7}{|l|}{ Type of complications } \\
\hline Anastomotic bleeding & $0(0.0 \%)$ & $1(3.4 \%)$ & & $0(0.0 \%)$ & $0(0.0 \%)$ & \\
\hline Intra-abdominal bleeding & $1(3.8 \%)$ & $1(3.4 \%)$ & & $0(0.0 \%)$ & $0(0.0 \%)$ & \\
\hline Canalization delay & $4(15.4 \%)$ & $3(10.3 \%)$ & & $2(10.0 \%)$ & $1(5.0 \%)$ & \\
\hline Neurological & $1(3.8 \%)$ & $0(0.0 \%)$ & & $0(0.0 \%)$ & $1(5.0 \%)$ & \\
\hline Cardiac & $1(3.8 \%)$ & $0(0.0 \%)$ & & $1(5.0 \%)$ & $1(5.0 \%)$ & \\
\hline Pulmonary & $3(11.5 \%)$ & $1(3.4 \%)$ & & $2(10.0 \%)$ & $1(5.0 \%)$ & \\
\hline Urinary & $1(3.8 \%)$ & $0(0.0 \%)$ & & $1(5.0 \%)$ & $0(0.0 \%)$ & \\
\hline Wound infection & $1(3.8 \%)$ & $1(3.4 \%)$ & & $1(5.0 \%)$ & $0(0.0 \%)$ & \\
\hline Other & $4(15.4 \%)$ & $3(10.3 \%)$ & & $2(10.0 \%)$ & $1(5.0 \%)$ & \\
\hline
\end{tabular}

supporting a clear superiority of robotic surgery [32, 33]. With regard to right colectomy and CME, only few studies fully addressed this topic. The main advantages favoring the robotic approach are the ameliorated vision of anatomic structures, the camera stability, and the EndoWrist $\odot$ technology which facilitates the construction of the anastomosis. Briefly, it has been postulated that the robotic platform reduces the surgeon fatigue by better ergonomics rather than it improves the patient outcome.

The technological improvements introducing the threedimensional vision in laparoscopic systems provided some of the advantages of robotic platform; thus, 3D laparoscopic surgery has emerged as a competitive alternative to the robotic one. However, the oncological and technical advantage of 3D laparoscopy over 2D is a matter of debate. The majority of studies comparing 2D and 3D were conducted in experimental and teaching setting while studies regarding clinical trial are sparse, heterogeneous, and deemed qualitative poor [34-36]. A meta-analysis of Zhao comparing the two kinds of vision showed that of 3D imaging in gastric cancer surgery could shorten operative time and reduce blood loss while it had no clear advantages in colorectal cancer patients [37]. Lee reported similar results except for a significantly lower rate of positive circumferential resection margin in 3D laparoscopic surgery for rectal cancer [38]. With regard to clinical relevance of $3 \mathrm{D}$ vision in right colectomy a careful literature search has been carried out. We were able to find a meta-analysis of Vettoretto and two further studies by Yoon and Bracale [39-41]. Neither Vettoretto nor Bracale specifically reported data on CME. The report of Yoon investigated the role of 3D laparoscopic in extended D3 lymphadenectomy (considered in Eastern countries as CME) both for right- and left-sided colorectal cancer. The paper had the limitation that the results were cumulatively reported; however, the study showed that the 3D system did not reduce the operative time and it appeared to be beneficial only in reducing blood loss and in increasing the number of harvested nodes [40].

To the best of our knowledge, there are no studies comparing robotic and 3D laparoscopic CME right colectomy. Given our experience in robotic and laparoscopic surgery $[18,30,42-46]$, we would try to make such a 
Table 3 Oncological data of included patients

\begin{tabular}{|c|c|c|c|c|c|c|}
\hline \multirow[t]{3}{*}{ Oncologic data } & \multicolumn{3}{|c|}{ Before propensity score matching } & \multicolumn{3}{|c|}{ After propensity score matching } \\
\hline & Robotic & 3D VLS & $p$ & Robotic & 3D VLS & $p$ \\
\hline & $n=26$ & $n=29$ & & $n=20$ & $n=20$ & \\
\hline T-Stage $(n, \%)$ & & & 0.044 & & & 0.048 \\
\hline Tis & $2(7.7 \%)$ & $5(17.2 \%)$ & & $2(10.0 \%)$ & $3(15.0 \%)$ & \\
\hline $\mathrm{T} 1$ & $1(3.8 \%)$ & $4(13.8 \%)$ & & $1(5.0 \%)$ & $4(20.0 \%)$ & \\
\hline $\mathrm{T} 2$ & $6(23.1 \%)$ & $2(6.9 \%)$ & & $5(25.0 \%)$ & 0 & \\
\hline $\mathrm{T} 3$ & $11(42.3 \%)$ & $17(58.6 \%)$ & & $8(40.0 \%)$ & $12(60.0 \%)$ & \\
\hline $\mathrm{T} 4$ & $6(23.1 \%)$ & $1(3.4 \%)$ & & $4(20.0 \%)$ & $1(5.0 \%)$ & \\
\hline T-Stage $(n, \%)$ & & & 0.570 & & & 0.730 \\
\hline Tis & $2(7.7 \%)$ & $5(17.2 \%)$ & & $2(10.0 \%)$ & $3(15.0 \%)$ & \\
\hline $\mathrm{T} 1-2$ & $7(3.8 \%)$ & $6(13.8 \%)$ & & $6(30.0 \%)$ & $4(20.0 \%)$ & \\
\hline T3-4 & $17(23.1 \%)$ & $18(6.9 \%)$ & & $12(60.0 \%)$ & $13(65.0 \%)$ & \\
\hline $\mathrm{N}-$ Stage $(n, \%)$ & & & 0.280 & & & 0.832 \\
\hline N0 & $17(65.4 \%)$ & $23(79.3 \%)$ & & $14(70.0 \%)$ & $15(75.0 \%)$ & \\
\hline N1 & $5(19.2 \%)$ & $5(17.2 \%)$ & & $4(20.0 \%)$ & $4(20.0 \%)$ & \\
\hline $\mathrm{N} 2$ & $4(15.4 \%)$ & $1(3.4 \%)$ & & $2(10.0 \%)$ & $1(5.0 \%)$ & \\
\hline Retrieved nodes $(n)$ & & & 0.571 & & & 0.976 \\
\hline$($ Mean \pm SD) & $20.4 \pm 10.8$ & $18.5 \pm 7.9$ & & $19.5 \pm 11.6$ & $19.8 \pm 8.8$ & \\
\hline (Median, range) & $19,8-58$ & $17,8-44$ & & $18,8-58$ & $17,8-44$ & \\
\hline Positive nodes & & & 0.607 & & & 0.931 \\
\hline$($ Mean \pm SD $)$ & $6.0 \pm 7.6$ & $2.3 \pm 1.8$ & & $2.6 \pm 2.6$ & $2.4 \pm 2.1$ & \\
\hline (Median, range) & $2,1-22$ & $2,1-6$ & & $2,1-8$ & $2,1-6$ & \\
\hline Node ratio $($ mean $\pm S D)$ & $0.23 \pm 0.08$ & $0.09 \pm 0.06$ & 0.529 & $0.10 \pm 0.09$ & $0.08 \pm 0.06$ & 0.665 \\
\hline
\end{tabular}

comparison especially with regard to intra-operatory findings and short-term outcome. In order to better analyze the potential technical advantages of 3D laparoscopy and to limit research bias, only a single surgeon case volume was considered.

Although our series showed no intra-operative complication even when more complex procedures were performed, we believe that robotic approach offers advantages in the treatment of locally advanced tumor and could facilitate the treatment of challenging conditions such as hemorrhagic situations due to SMV injury as well as reported in other studies [47, 48]. Another pro-favoring the robotic approach was the use of the "firefly" mode to check blood supply and to observe lymphatic pathway depicted by injection of Indocyanine Green [49]. At present, this advantage is being overcome by various 3D laparoscopic devices which offer the same opportunity (not the one we used for this study). However, we did not routinely use the Indocyanine Green in right colectomy. Finally, as for the whole intra-operative aspect concerning the surgeon perception, we state that during the 3D laparoscopy, the surgeons may experience initial visual fatigue and headache due to the use of the glasses for $3 \mathrm{D}$ vision. Such discomfort improves over time as the experience progresses, but we recognize that it might represent a limitation.
As reported in the results section, there were not statistically significant differences between the robotic and the 3D laparoscopic approach except for the duration of surgery which resulted longer in the robotic group. Two factors potentially affecting operative time have been investigated: local extension of neoplasm (the T stage) and the concomitant procedure. Although different in the entire series, after propensity score matching, the locally advanced tumor as T3-T4 stages was comparable with a slightly higher rate in the 3D group (65\% vs $60 \%$ ). The degree of difficulty of associated procedures was herein evaluated by grading the level of complexity and relative operative time by a blinded senior staff surgeon. Again, no statistically differences were noted in the two groups; hence, we believe that the operative time might only depend on the approach itself. Further studies are needed in order to assess the time of each procedural step to better address the key point of the wasted time.

A careful attention must be paid in evaluating postoperative complications. Robotic approach showed morbidity rate almost twice higher even if the difference did not reach statistically significance maybe for the sample size. About that, the results concerning postoperative morbidity were critically analyzed. Complications in both groups were almost all Clavien I-II grade and were mostly nonsurgical related. Furthermore, the only one Clavien III 
complication which occurred in the 3D group could be over-graded as analytically described in the results section.

One of the most important limitations of the present report is that it is a retrospective observational study encompassing a small number of cases. As stated above, only a small number of patients underwent CME; thus, it is the reason for our sample size. However, it is important to consider that the propensity score model allowed us to compare two similar groups. Being single surgeon experience, on the one hand, there may be a criticism about the lack of reproducibility due to different skills and learning curve in robotic and laparoscopic surgery among different surgeons; on the other hand, the bias due to the difference ability between more operators has been avoided.

Since the outcomes of both robotic and 3D laparoscopic right colectomy with CME could be considered similar, a last but not least important issue must be evaluated: the costs of the two procedures. The cost of purchase, periodic services, devices, and consumption of operating room resources by the robotic system are considerably higher than those of 3D laparoscopic system [50-53]. A recent report by Merola calculated the costs of robotic versus laparoscopic right colectomy for the Italian National Health System, reporting that the total mean cost of robotic right colectomy was almost twice as compared to laparoscopic one [52].

In conclusion, our preliminary experience showed the 3D laparoscopic approach allowed a safe and effective CME with CVL and IIA in right colectomy, providing short-term outcomes similar to the same robot-assisted procedure. The 3D vision revealed an important advantage in order to achieve the correct identification of anatomic landmarks and the precision required by some difficult laparoscopic movements such as suturing and making knot. Taking into account the resource availability, the higher costs and the longer operative time of robotic procedure, the 3D laparoscopic approach could be considered a safe and reliable alternative in performing right colectomy with CME. The robotic approach should be considered as a first choice approach for challenging situations such as obese patient or when more complex concomitant procedures are required.

Funding The authors declare that there is no funding regarding the publication of this article.

\section{Compliance with ethical standards}

Disclosures Graziano Ceccarelli, Gianluca Costa, Valentina Ferraro, Michele De Rosa, Fabio Rondelli, and Walter Bugiantella have no conflicts of interest or financial ties to disclose.

\section{References}

1. Hohemberger W, Weber K, Matzel K, Papadopoulos T, Merkel S (2009) Standardized surgery for colonic cancer: complete mesocolic excision and central ligation-technical notes and outcome. Colorectal Dis 11(4):354-364

2. Bokey EL, Chapuis PH, Dent OF, Mander BJ, Bissett IP, Newland RC (2003) Surgical technique and survival in patients having a curative resection for colon cancer. Dis Colon Rectum 46:860-866

3. Wibe A, Moller B, Norstein J, Carlsen E, Wiig JN, Heald RJ, Langmark F, Myrvold HE, Soreide O, Norwegian Rectal Cancer G (2002) A national strategic change in treatment policy for rectal cancer-implementation of total mesorectal excision as routine treatment in Norway. A national audit. Dis Colon Rectum 45(7):857-866

4. West NP, Morris EJ, Rotimi O, Cairns A, Finan PJ, Quirke P (2008) Pathology grading of colon cancer surgical resection and its association with survival: a retrospective observational study. Lancet Oncol 9(9):857-865

5. Chow CF, Kim SH (2014) Laparoscopic complete mesocolic excision: West meets East. World J Gastroenterol 20(39):14301-14307

6. Veldkamp R, Kuhry E, Hop WC, Jeekel J, Kazemier G, Bonjer HJ, Haglind E, Påhlman L, Cuesta MA, Msika S, Morino M, Lacy AM, COlon cancer Laparoscopic or Open Resection Study Group (COLOR) (2005) Laparoscopic surgery versus open surgery for colon cancer: short-term outcomes of a randomised trial. Lancet Oncol 6:477-484

7. Guillou PJ, Quirke P, Thorpe H, Walker J, Jayne DG, Smith AM, Heath RM, Brown JM, MRC CLASICC trial group (2005) Shortterm end points of conventional versus laparoscopic assisted surgery in patients with colorectal cancer (MRC CLASSIC trial): multicentre, randomised controlled trial. Lancet 365:1718-1726

8. Green BL, Marshall HC, Collinson F, Quirke P, Guillou P, Jayne DG, Brown JM (2013) Long-term follow-up of the medical research council CLASSIC trial of conventional versus laparoscopically assisted resection in colorectal cancer. Br J Surg 100:75-82

9. Fleshman J, Sargent DJ, Green E, Anvari M, Stryker SJ, Beart RW Jr, Hellinger M, Flanagan R Jr, Peters W, Nelson H, Clinical Outcomes of Surgical Therapy Study Group (2007) Laparoscopic colectomy for cancer is not inferior to open surgery based on 5-year data from COST study Group trial. Ann Surg 246:655-662

10. Leal Ghezzi T, Campos Corleta O (2016) 30 years of robotic surgery. World J Surg 40:2550-2557

11. Sinha RY, Raje SR, Rao GA (2017) Three-dimensional laparoscopy: principles and practice. J Minimal Access Surg 13(3):165-169

12. Abdelrahman M, Belramman A, Salem R, Patel B (2018) Acquiring basic and advanced laparoscopic skills in novices using twodimensional (2D), three-dimensional (3D) and ultra-high definition $(4 \mathrm{~K})$ vision systems: a randomized control study. Int J Surg 53:333-338

13. Emile SH, Elfeki H, Shalaby M, Sakr A, Bassuni M, Christensen P, Wexner SD (2019) Intracorporeal versus extracorporeal anastomosis in minimally invasive right colectomy: an updated systematic review and meta-analysis. Tech Coloproctol 23(11):1023-1035

14. Bollo J, Turrado V, Rabal A, Carrillo E, Gich I, Martinez MC, Hernandez P, Targarona E (2020) Randomized clinical trial of intracorporeal versus extracorporeal anastomosis in laparoscopic right colectomy (IEA trial). Br J Surg 107(4):364-372

15. von Elm E, Altman DG, Egger M, Pocock SJ, Gøtzsche PC, Vandenbroucke JP (2008) STROBE initiative. The strengthening the reporting of observational studies in epidemiology (STROBE) 
statement: guidelines for reporting observational studies. J Clin Epidemiol 61(4):344-349

16. Clavien PA, Barkun J, de Oliveira ML, Vauthey JN, Dindo D, Schulick RD, de Santibañes E, Pekolj J, Slankamenac K, Bassi C, Graf R, Vonlanthen R, Padbury R, Cameron JL, Makuuchi M (2009) The Clavien-Dindo classification of surgical complications: five-year experience. Ann Surg 250(2):187-196

17. de Santibañes M, Alvarez FA, Sieling E, Vaccarezza H, de Santibañes E, Vaccaro CA (2015) Postoperative complications at a university hospital: is there a difference between patients operated by supervised residents vs. trained surgeons? Langenbecks Arch Surg 400(1):77-82

18. Casciola L, Codacci-Pisanelli M, Ceccarelli G, Bartoli A, Di Zitti L, Patriti A (2008) A modified umbilical incision for specimen extraction after laparoscopic abdominal surgery. Surg Endosc 22(3):784-786

19. Storli KE, Sondenaa K, Furnes B, Eide GE (2013) Outcome after introduction of complete mesocolic excision for colon cancer is similar for open and laparoscopic treatments. Dig Surg 30:317-327

20. Gouvas N, Agalianos C, Papaparaskeva K, Perrakis A, Hoemberger W, Xynos E (2016) Surgery along the embryological planes for colon cancer: a systematic review of complete mesocolic excision. J Colorectal Dis 31(9):1577-1594

21. Bertelsen CA, Neuenschwander AU, Jansen JE, Tenma JR, Wilhelmsen M, Kirkegaard-Klitbo A, Iversen ER, Bols B, Ingeholm P, Rasmussen LA, Jepsen LV, Born PW, Kristensen B, Kleif J (2019) 5-year outcome after complete mesocolic excision for right-sided colon cancer: a population-based cohort study. Lancet Oncol 20(11):1556-1565

22. Robinson TN, Walston JD, Brummel NE, Deiner S, Brown CH, Kennedy M, Hurria A (2015) Frailty for surgeons: review of a national institute on aging conference on frailty for specialists. J Am Coll Surg 221(6):1083-1092

23. Koh FH, Tan KK (2019) Complete mesocolic excision for colon cancer: is it worth it? J Gastrointest Oncol 10(6):1215-1221

24. Athanasiou CD, Markides GA, Kotb A, Jia X, Gonsalves S, Miskovic D (2016) Open compared with laparoscopic complete mesocolic excision with central lymphadenectomy for colon cancer: a systematic review and meta-analysis. Colorectal Dis 18(7):O224-O235

25. Chaouch MA, Dougaz MW, Bouasker I, Jerraya H, Ghariani W, Khalfallah M, Nouira R, Dziri C (2019) Laparoscopic versus open complete mesocolon excision in right colon cancer: a systematic review and meta-analysis. World J Surg 43(12):3179-3190

26. Bertelsen CA (2017) Complete mesocolic excision an assessment of feasibility and outcome. Dan Med J 64(2):B5334

27. Prevost GA, Odermatt M, Furrer M, Villiger P (2018) Postoperative morbidity of complete mesocolic excision and central vascular ligation in right colectomy: a retrospective comparative cohort study. World J Surg Oncol 16(1):214

28. Allaix ME, Degiuli M, Bonino MA, Arezzo A, Mistrangelo M, Passera R, Morino M (2019) Intracorporeal or extracorporeal ileocolic anastomosis after laparoscopic right colectomy: a doubleblinded randomized controlled trial. Ann Surg 270(5):762-767

29. Jamali FR, Soweid AM, Dimassi H, Bailey C, Leroy J, Marescaux J (2008) Evaluating the degree of difficulty of laparoscopic colorectal surgery. Arch Surg 143(8):762-767

30. Casciola L, Ceccarelli G, Di Zitti L, Valeri R, Bellochi R, Bartoli A, Barbieri F, Spaziani A, D’Ajello M (2003) Laparoscopic right hemicolectomy with intracorporeal anastomosis. Technical aspects and personal experience. Minerva Chir 58(4):621-627

31. Anania G, Agresta F, Artioli E, Rubino S, Resta G, Vettoretto N, Petz WL, Bergamini C, Arezzo A, Valpiani G, Morotti C, Silecchia G, SICE CoDIG (Colon Dx Italian Group) (2019) Laparoscopic right hemicolectomy: the SICE (Società Italiana di Chirurgia Endoscopica e Nuove Tecnologie) network prospective trial on 1225 cases comparing intra corporeal versus extra corporeal ileo-colic side-to-side anastomosis. Surg Endosc. https ://doi.org/10.1007/s00464-019-07255-2

32. Ng KT, Tsia AKV, Chong VYL (2019) Robotic versus conventional laparoscopic surgery for colorectal cancer: a systematic review and meta-analysis with trial sequential analysis. World $\mathbf{J}$ Surg 43(4):1146-1161

33. Ngu JC, Kim SH (2019) Robotic surgery in colorectal cancer: the way forward or a passing fad. J Gastrointest Oncol 10(6):1222-1228

34. Sørensen SM, Savran MM, Konge L, Bjerrum F (2016) Threedimensional versus two-dimensional vision in laparoscopy: a systematic review. Surg Endosc 30(1):11-23

35. Fergo C, Burcharth J, Pommergaard HC, Kildebro N, Rosenberg J (2017) Three-dimensional laparoscopy vs 2-dimensional laparoscopy with high-definition technology for abdominal surgery: a systematic review. Am J Surg 213(1):159-170

36. Zundel S, Lehnick D, Heyne-Pietschmann M, Trück M, Szavay P (2019) A suggestion on how to compare 2D and 3D laparoscopy: a qualitative analysis of the literature and randomized pilot study. J Laparoendosc Adv Surg Tech A 29(1):114-120

37. Zhao B, Lv W, Mei D, Luo R, Bao S, Huang B, Lin J (2020) Comparison of short-term surgical outcome between 3D and 2D laparoscopy surgery for gastrointestinal cancer: a systematic review and meta-analysis. Langenbecks Arch Surg 405(1):1-12

38. Lee Y, Lee CM, Jang YJ, Park S, Park SH, Mok YJ, Kim JH (2019) Comparison of short-term outcomes using three-dimensional and two-dimensional laparoscopic gastrectomy for gastric cancer. J Laparoendosc Adv Surg Tech A 29(7):886-890

39. Vettoretto N, Reggiani L, Cirocchi R, Henry BM, Covarelli P, D'Andrea V, Popivanov G, Randolph J (2018) Three-dimensional versus two-dimensional laparoscopic right colectomy: a systematic review and meta-analysis. Int $\mathbf{J}$ Colorectal Dis 33(12):1799-1801

40. Yoon J, Kang SI, Kim MH, Kim MJ, Oh HK, Kim DW, Kang SB (2019) Comparison of short-term outcomes between 3D and 2D imaging laparoscopic colectomy with D3 lymphadenectomy for colon cancer. J Laparoendosc Adv Surg Tech A 29(3):340-345

41. Bracale U, Merola G, Rizzuto A, Pontecorvi E, Silvestri V, Pignata G, Pirozzi F, Cuccurullo D, Sciuto A, Corcione F (2020) Does a 3D laparoscopic approach improve surgical outcome of mininvasive right colectomy? A retrospective case-control study. Updates Surg. https://doi.org/10.1007/s13304-020-00755-0

42. Patriti A, Ceccarelli G, Bartoli A, Spaziani A, Biancafarina A, Casciola L (2009) Short- and medium-term outcome of robotassisted and traditional laparoscopic rectal resection. JSLS 13(2):176-183

43. Ceccarelli G, Patriti A, Biancafarina A, Spaziani A, Bartoli A, Bellochi R, Casciola L (2009) Intraoperative and postoperative outcome of robot-assisted and traditional laparoscopic Nissen fundoplication. Eur Surg Res 43(2):198-203

44. Pigazzi A, Luca F, Patriti A, Valvo M, Ceccarelli G, Casciola L, Biffi R, Garcia-Aguilar J, Baek JH (2010) Multicentric study on robotic tumor-specific mesorectal excision for the treatment of rectal cancer. Ann Surg Oncol 17(6):1614-1620

45. Caruso S, Patriti A, Marrelli D, Ceccarelli G, Ceribelli C, Roviello F, Casciola L (2011) Open vs robot-assisted laparoscopic gastric resection with D2 lymph node dissection for adenocarcinoma: a case-control study. Int J Med Robot 7(4):452-458

46. Ceccarelli G, Gusai G, Rondelli F, Balestra F, De Rosa M (2019) Video-robotic aneurismectomy for splenic artery aneurysm: case report and literature review. Minim Invasive Ther Allied Technol $28: 1-6$

47. Lujan HJ, Plasencia G, Rivera BX, Molano A, Fagenson A, Jane LA, Holguin D (2018) Advantages of robotic right colectomy with 
intracorporeal anastomosis. Surg Laparosc Endosc Percutan Tech 28(1):36-41

48. Yozgatli TK, Aytac E, Ozben V, Bayram O, Gurbuz B, Baca B, Balik E, Hamzaoglu I, Karahasanoglu T, Bugra D (2019) Robotic complete mesocolic excision versus conventional laparoscopic hemicolectomy for right-sided colon cancer. J Laparoendosc Adv Surg Tech A. https://doi.org/10.1089/lap.2018.0348

49. Kobiela J, Bertani E, Petz W, Crosta C, De Roberto G, Borin S, Ribero D, Baldassari D, Spychalski P, Spinoglio G (2019) Double indocyanine green technique of robotic right colectomy: introduction of a new technique. J Minim Access Surg 15(4):357-359

50. DeSouza A, Prasad LM, Park JJ, Marecik SJ, Blumetti J, Abcarian H (2010) Robotic assistance in right hemicolectomy: is there a role? Dis Colon Rectum 53:1000-1006

51. Rondelli F, Balzarotti R, Villa F, Guerra A, Avenia N, Mariani E, Bugiantella W (2015) Is robot-assisted laparoscopic right colectomy more effective than the conventional laparoscopic procedure? A meta-analysis of short-term outcomes. Int J Surg $18: 75-82$
52. Merola G, Sciuto A, Pirozzi F, Andreuccetti J, Pignata G, Corcione F, Milone M, De Palma GD, Castaldo R, Pecchia L, Ceccarelli G, Bracale U (2019) Is robotic right colectomy economically sustainable? A multicentre retrospective comparative study and cost analysis. Surg Endosc. https://doi.org/10.1007/s00464-01907193-z

53. Spinoglio G, Bianchi PP, Marano A, Priora F, Lenti LM, Ravazzoni F, Petz W, Borin S, Ribero D, Formisano G, Bertani E (2018) Robotic versus laparoscopic right colectomy with complete mesocolic excision for the treatment of colon cancer: perioperative outcomes and 5-year survival in a consecutive series of 202 patients. Ann Surg Oncol 25(12):3580-3586

Publisher's Note Springer Nature remains neutral with regard to jurisdictional claims in published maps and institutional affiliations. 